\title{
A New Outlook of Complementizers
}

\author{
Ji Young Shim ${ }^{1, *}$ and Tabea Ihsane ${ }^{2,3}$ \\ 1 Department of Linguistics, University of Geneva, 24 rue du Général-Dufour, 1211 Geneva, Switzerland \\ 2 Department of English, University of Geneva, 24 rue du Général-Dufour, 1211 Geneva, Switzerland; \\ tabea.ihsane@unige.ch \\ 3 University Priority Research Program (URPP) Language and Space, University of Zurich, Freiestrasse 16, \\ 8032 Zurich, Switzerland \\ * Correspondence: jiyoung.shim@unige.ch; Tel.: +41-22-379-7236
}

Academic Editor: Usha Lakshmanan

Received: 28 February 2017; Accepted: 16 August 2017; Published: 4 September 2017

\begin{abstract}
This paper investigates clausal complements of factive and non-factive predicates in English, with particular focus on the distribution of overt and null that complementizers. Most studies on this topic assume that both overt and null that clauses have the same underlying structure and predict that these clauses show (nearly) the same syntactic distribution, contrary to fact: while the complementizer that is freely dropped in non-factive clausal complements, it is required in factive clausal complements by many native speakers of English. To account for several differences between factive and non-factive clausal complements, including the distribution of the overt and null complementizers, we propose that overt that clauses and null that clauses have different underlying structures responsible for their different syntactic behavior. Adopting Rizzi's (1997) split CP (Complementizer Phrase) structure with two $C$ heads, Force and Finiteness, we suggest that null that clauses are FinPs (Finiteness Phrases) under both factive and non-factive predicates, whereas overt that clauses have an extra functional layer above FinP, lexicalizing either the head Force under non-factive predicates or the light demonstrative head $d$ under factive predicates. These three different underlying structures successfully account for different syntactic patterns found between overt and null that clauses in various contexts.
\end{abstract}

Keywords: (null) complementizer; (non-)factive; clausal complements; selection

\section{Introduction}

When a verb takes a clausal complement, it may be headed by an overt lexical complementizer (COMP), which is obligatory in many languages in the world. Yet, languages vary with respect to whether verbs taking a finite clausal complement allow the deletion of the COMP. For instance, the finite declarative COMP that can be freely omitted in clausal complements of non-factive verbs in English, as shown in (1a). In contrast, the deletion of the COMP under factive verbs (e.g., know, realize, regret) seems to be of a more contentious issue: since the seminal work by Kiparsky and Kiparsky [1], it has long been assumed that that cannot be deleted in clausal complements of factive verbs, as in (1b).

1. a. Dean believes/says/thinks that Lily doesn't eat vegetables

non-factive

b. Dean knows/realizes/regrets *(that) Lily doesn't eat vegetables

factive

Much previous work on the English COMP that seems to divide into two major schools. The first approach focuses on clausal complements of non-factive predicates of the type in (1a), where overt and null COMPs freely alternate. The main goal of this research is to investigate the structures of overt 
and null COMPs, and explain how the null COMP is allowed in addition to the overt COMP in this environment [2-4]. The second approach explores clausal complements of factive predicates of the type in (1b), assuming that the COMP is obligatory [5-8].

However, this long-held assumption between factive and non-factive verbs with regard to the deletion of COMP seems to blur in contemporary English. We conducted an informal survey of acceptability judgment task involving various sentence pairs, each sentence constructed with the COMP that in its clausal complement and without the COMP that in the same condition. The results from 10 native speakers of various varieties of English (five American English, two Canadian English, two British English, and one New Zealand English), show that the COMP that can be optional under both factive and non-factive predicates alike except with the verb regret, after which that is obligatory. The examples below show this new pattern of COMP deletion under factive predicates.

2. a. Dean knows/realizes that Lily doesn't eat vegetables

\section{b. Dean regrets *(that) Lily doesn't eat vegetables}

To our knowledge, there is no study available that looks into the distribution of null COMPs in factive complements of the type in (2a), whose patterns differ from the traditional judgments reported in the literature. Interestingly, the contrast between (2a) and (2b) corroborates Karttunen's observation that there are two types of factive verbs, semi-factives (e.g., know, realize) and strong/true factives (e.g., regret) [9]. Semi-factives are distinguished from strong factive predicates, for they lose their factivity in questions and conditionals. ${ }^{1}$

The goal of the present study is to develop an analysis of the distribution of overt and null COMPs in clausal complements of non-factive and factive predicates provided in (1) and (2). One may question the validity of the data presented in (2), as they were collected from a small number of people via a rather informal data collection method. While we acknowledge that we need to conduct a large-scale experiment with more test materials and participants to confirm the results, we are confident to present our data in this paper due to the following two reasons.

First, despite its rather informal nature, a small-scale acceptability judgment task that we used in our study has been predominantly exercised as a major data collection method in the field of generative linguistics, based on which diverse syntactic theories have been proposed. In this regard, our method is no different from most studies available and the number of informants we had, 10, is considered relatively high in practice; many linguists often rely on their own judgments alone. In addition, a recent study [11] that compares the results of the so-called traditional informal judgment collection methods with the results of large-scale formal judgment collection methods reveals that the differences between these two methods are relatively small, a convergence rate of $95 \%$, with a margin of error of $\pm 5.3-5.8 \%$ ([11], p. 229). ${ }^{2}$

Thus, we include this new set of data in (2) in addition to those that are more traditionally assumed in the literature in developing our analysis. The central hypothesis is that overt that clauses and null that clauses have different underlying structures that result in different syntactic behavior. We will argue that overt that complements of non-factive predicates and overt that complements of factive predicates also have different underlying structures, despite their resemblance on the surface.

The remainder of the paper is organized as follows. In Section 2, we briefly discuss previous accounts of the distribution of null COMPs and show that none of the existing accounts can fully explain various distributional patterns of null COMPs. Thus, we propose a new outlook of syntactic structures for overt and null COMPs in factive and non-factive complements. Section 3 extends the analyses proposed in Section 2 to sentential subjects and concludes the paper.

\footnotetext{
The properties of these different factive predicates are further discussed in Hooper and Thompson [10]. We thank the anonymous reviewer who brought this study to our attention.
} 


\section{Different Structures for Overt and Null Complementizers}

Most studies on the distribution of the null COMP have an overarching proposal that overt that clauses and null that clauses have an identical syntactic structure, in which the COMP, either overt or null, represents a $\mathrm{C}$ head. Under this view, both overt and null that clauses are predicted to show the same or at least very similar syntactic distributions. However, this prediction is not borne out. It is well known that while the so-called "root transformations" (RTs) or "main clause phenomena" (MCP) or "embedded root phenomena" (ERP) such as argument topicalization are permitted when the COMP is overt, they are not allowed when the COMP is null as shown in (3) [12].

3. Dean believes/thinks/says *(that) vegetables Lily doesn't eat vegetables

Doherty argues that the unified CP (Complementizer Phrase) analysis for overt and null COMPs fails to account for different syntactic patterns between overt and null that clauses [13]. He instead proposes that overt that clauses and null that clauses are structurally distinguished, the former being a $\mathrm{CP}$ and the latter being an IP (Inflectional Phrase). In addition, he adopts The Adjunction Prohibition [14], which forbids adjunction to a phrase that is s(ementically)-selected by a lexical head. Thus, in an overt that clause where the IP is selected by a $C$ head, which is not a lexical head, IP adjunction (e.g., topicalization) is possible. On the other hand, IP adjunction is banned in a null that clause where the IP is selected by a lexical verb, not by a $\mathrm{C}$ head. This explains why the COMP must be present in (3).

While Doherty's proposal accounts for the contrast between overt and null that clauses under non-factive predicates, it cannot be extended to clausal complements of factive predicates. Despite the presence of the COMP that, RTs are banned in the clausal complement of a factive predicate $[8,14-17]$ as exemplified in (4). ${ }^{3}$

4. $\quad$ a. $\quad$ Mary realizes that this book John read

[19] (p. 52)

b. $\quad$ ?*I regret that Mary my antics upset as much as they did

[20] (p. 179)

There are, however, speakers who allow RTs in clausal complements of some factive predicates, as a reviewer points out. And this is precisely limited to the so-called semi-fative predicates, which also allow the null COMP in their complements as in (2a). Thus, it seems that while true factives behave differently from non-factives with regard to COMP deletion and RTs, semi-factives may pattern along with non-factives.

5. a. The public doesn't realize that even more corrupt is the Republic Party

[15] (p. 480)

b. I discovered that this book, it has the recipes in it

[15] (p. 481)

To explain several differences found in clausal complements of factive and non-factive predicates, researchers have proposed two contrasting analyses. A more traditional view is that clausal complements of factive predicates are nominal in nature, and they are in fact a nominal complement in which a nominal head selects the clausal complement $[1,8,19,21]$. In other words, the structure of factive clausal complements is more complex than that of non-factive complements. On the contrary, more recent studies propose that the structure of factive complements is simpler than that of non-factive complements, and the limited syntactic behavior of factive complements is related to its simpler/reduced CP structure [22,23].

3 Factive and non-factive complements are further distinguished from each other in several ways, including the presence vs. absence of presupposition and the presence vs. absence of (weak-) islandhood, which will not be further discussed due to the limited space and scope of this paper. We refer interested readers to Shim and Ihsane and the references therein [18]. 
Building on the above-mentioned views that (a) the structure of overt that clauses is more complex than the structure of null that clauses, (b) factive complements are nominal in nature, and (c) the structure of non-factive that complements is richer than the structure of factive that complements, we propose the following underlying structures of clausal complements of non-factive and factive predicates with an overt COMP and a null COMP.

Non-factive complements

6. a. [ForceP Force $=$ that $($ Topic $)($ Focus $)[$ FinP Fin $=\varnothing]]$

b. $\quad b[$ FinP Fin $=\varnothing]$ overt COMP

null COMP

Factive complements

7. $[d \mathrm{P} d=$ that $[$ FinP Fin $=\varnothing]]$

The examples in (6) show that the underlying structure of non-factive complements have two variants; when the COMP is overt, it is a ForceP, whose head is lexicalized by that. When the COMP is null, Force is not projected, a possibility hinted at but not discussed in Rizzi and Shlonsky [24]. On the other hand, true factive predicates such as regret, which do not allow a null COMP and RTs in its clausal complement, take a nominal complement, whose head is lexicalized by that, as shown in (7). ${ }^{4}$ Finally, semi-factive predicates such as know and realize, may take the clausal complements in (6) or the nominal complement in (7). For speakers who permit neither the null COMP nor RTs in this environment, they have access to the structure in (7) for both strong and semi-factives. In contrast, for those who allow COMP deletion and RTs, as in (2a) and (5), the structures in (6) represent the clausal complements of both non-factive and semi-factive predicates.

In what follows, we will provide evidence supporting the structures proposed in (6) and (7), which further explain different syntactic behavior observed between overt that clauses and null that clauses and between non-factive and factive complements.

\subsection{Non-Factive Clausal Complements}

Rizzi [25] proposes an articulated structure of COMPs, splitting C into two functional categories, Force and Fin(iteness), between which Topic and Focus may be optionally projected, as illustrated in (8). While the head Force encodes a sentence type, such as a declarative or an interrogative, the head Fin specifies whether a sentence is finite or non-finite. Rizzi further argues that the finite declarative COMP che in Italian represents a Force head, higher than topicalized and focalized elements.

8. Force (Topic) (Focus) Fin IP

Rizzi suggests that the COMP that also represents Force in English, similar to the Italian COMP che, which corresponds to the structure of the overt COMP proposed in (6a). On the other hand, the null COMP originates under Fin, as shown in (6b). When Topic or Focus is optionally projected between Force and Fin, the Force-Finiteness system must remain split, Force being lexicalized by that and Fin being realized by the null COMP. When there is no intervening head such as Topic or Focus, the Force-Finiteness system can be expressed on a single head in English, as a result of which the overt COMP and the null COMP alternate.

What is not clear, though, is the process of expressing the Force-Finiteness system on a single head, when neither Topic nor Focus are projected. Rizzi explains that the split CP structure is forced by the activation of Topic and Focus [25] (p. 314). Otherwise, only a single C head is projected for economy reasons, which can remain null or be spelled out as that. In other words, the structure of

4 The head $d$ in (7) is light in the sense that it lacks $\varphi$-features. We will further explain the nature of the light $d$ head in Section 2.2. 
the COMP that can be either the one in (6a), where two $C$ heads, Force and Fin, remain separate or it can be a single $\mathrm{CP}$ structure where the $\mathrm{C}$ head is an amalgam of Force and Fin. On the other hand, the structure of the null COMP represents a single $\mathrm{CP}$ structure.

We adopt Rizzi's insight that the COMP that lexicalizes a higher $C$ head, Force, and the null COMP originates under Fin, a lower $\mathrm{C}$ head in the split/multiple CP structures. But we depart from him in that Force and Fin make a single head when there is no intervening head such as Topic or Focus. Rizzi argues that there is cross-linguistic variation in the mechanism of expressing Force and Finiteness on a single head; for instance, while such an option is available in English, it is not available in Italian. This explains why the null COMP is possible in English, but not in Italian. However, Rizzi does not explain why forming the complex Force + Fin head is only allowed in English, but not in Italian.

Instead, we take a unified view that Force and Fin remain separate in the syntactic derivation both in English and Italian. Thus, when the lower $C$ head, Fin, is projected, this $C$ head is phonetically empty, resulting in a null COMP in English, as in (6b). When an additional $C$ layer is projected in the structure, this higher $C$ head is spelled out as that, resulting in an overt COMP as in (6a). As for Italian, we follow Rizzi and assume that Force and Fin also remain separate and the head Force is lexicalized by che and Fin is null. But we take a difference stance from him to account for the cross-linguistic variation between these two languages. The existence of the null COMP in English, but its absence in Italian is due to different selectional requirements of a predicate in these languages. When a predicate selects a clausal complement, it can be either a ForceP (overt COMP) or a FinP (null COMP) in English. In Italian, on the other hand, a predicate may select only a ForceP (overt COMP). ${ }^{5}$ We leave this topic, which is beyond the scope of this paper, for future research.

The structures in (6) can explain why RTs are possible when the COMP is overt in (3). In an overt that clause (6a), Topic and Focus may be optionally projected between ForceP and FinP, allowing RTs. On the other hand, it is not self-evident why Topic and/or Focus cannot be projected in (6b), assuming that the projection of Topic and/or Focus is optional above Fin: Top(ic)P and Foc(us)P should be allowed above FinP in (6b), if these projections are optional. If this were the case, RTs would be possible in (3) when the COMP is null, contrary to fact. How can we then rule out the projection of TopP and FocP in $(6 b)$ ?

Rizzi argues that the split CP structure is forced by the activation of Topic and Focus [25] (p. 314), explaining that in a single CP structure such as the one in (6b), Topic and Focus are missing. Once again, however, this seems to be limited to English, not in Italian. For unknown reasons, it seems that while Topic and Focus may or may not be activated in English, allowing a split CP structure of a single $\mathrm{CP}$ structure, they must be always activated in Italian, for a single CP structure is not allowed in this language.

Under our unified analysis that Force and Fin remain separate both in English and Italian, this can be answered differently in terms of selectional requirements of the matrix predicate. When a predicate selects a clausal complement/CP in English, the clausal complement must be either a ForceP or a FinP, whose head corresponds to $\mathrm{C}$. The projection of Topic and Focus is optional, expressing the information structure of a clause. That is, neither TopP nor FocP are qualified to be a complement of a predicate, which cannot be optional. In other words, when TopP or FocP is projected above FinP in (6b), it cannot be directly selected by the matrix predicate. This explains why RTs are banned in a null that clause in English.

We have proposed that overt that clauses are ForcePs and null that clauses are FinPs under non-factive predicates. In support of our proposal that ForceP is not projected when the COMP is null as in (6b), the following line of thought is considered. First, adopting Rizzi's original proposal, the Fin head contains a feature [+finite] or [-finite], perhaps along with $\varphi$-features. Second, a functional

5 Rizzi expresses that a matrix predicate selects ForceP only (both in English and Italian) [25]. 
category may remain phonetically null if there is no lexical item to spell it out. We suggest that English has no lexical item to spell out Fin with [+finite], whereas Fin with [-finite] may be spelled out as for. ${ }^{6}$

One may wonder how a null that clause is interpreted as a declarative sentence if Force is not projected, assuming that Force is the locus of deciding a sentence type (e.g., declarative, interrogative). Roberts argues that ForceP is either absent or inert in root declaratives, suggesting that root declaratives are the unmarked clause type [26]. On the other hand, Roberts assumes that ForceP is present in embedded clauses, in which the COMP that raises from Fin to Force. While we agree with Robert's idea that root declaratives are the unmarked clause type, the question arises why only in root clauses, not in embedded clauses, declaratives are unmarked. Roberts does not provide an answer to this question, and we adopt his suggestion for root clauses and hypothesize that in embedded clauses too, declaratives are the unmarked clause type (in English). In other words, declarative force may not be encoded on Force per se, but it is granted as the unmarked sentence type at the level of FinP both in matrix and embedded clauses. ${ }^{7}$ On the other hand, the information delivering other sentence types than declaratives (e.g., interrogatives) is encoded on Force by their relative features, for instance [+wh]. On this assumption, the label of Force in (6a) seems to be misleading, and needs to be reconsidered. Nonetheless, we will continue to use the label Force in this paper for expository purposes. ${ }^{8}$

Researchers argue that the COMP delivers the information of the clausal type [27] or the specification of force [28]. Yet, our proposal challenges this view: the COMP that originates under the head Force, but declarative force itself is not encoded on Force per se but it is granted as the unmarked sentence type at the level of FinP. To support our new outlook of COMPs, we provide cross-linguistic evidence from Korean, a language that is head-final (Subject-Object-Verb order) and agglutinative in its morphology. In (9), the COMP ko does not convey the force of the embedded clause, and the

6 Alternatively, one may assume that Fin with [+finite] is spelled out as that, which raises on to Force [26]. On this assumption, however, it is not clear how to account for a null COMP. It seems that Fin with [+finite] is then spelled out as that or phonetically null.

7 This may not be universal across languages. While it is reasonable to assume that ForceP may be absent in English root declaratives, it is always projected in Korean. As shown in (i) both the matrix sentence and the embedded clause must be marked with the declarative morpheme $-t a$ in a formal speech.
i. Joon-un
Mari-ka
yeppu-*(ta)-ko
sayngkakha-n-*(ta)
Joon-TOP
Mari-NOM pretty-DECL-COMP
think-PRES-DECL
'Joon thinks that Mari is pretty.'

An anonymous reviewer points out that the declarative morpheme - $t a$ is missing in the so-called "panmal" or - $a / e$ style of speech, which may indicate that ForceP may be absent in Korean root declaratives. The "panmal" or -a/e style of speech is an informal, non-polite colloquial speech act and data in question are provided in (ii) below.

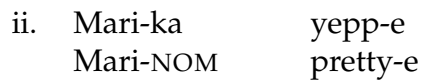
'(I think that) Mari is pretty.'

The example in (ii) is marked by the informal sentence ending particle $-e$ instead of the formal declarative marker -ta. The reason that the declarative morpheme $-t a$ is missing in the matrix clause in (ii) is related to the speech act of the sentence; the formal declarative marker - $t a$ cannot appear in the informal colloquial "panmal" or -a/e style of speech. Instead, the sentence type information (in this case, declarative) may be encoded on the morpheme $-e$ in (ii).

8 Alternatively, we may wonder whether the head Force could be re-labelled into Assert, following the insight suggested by Hooper \& Thompson [10]. Assertion is defined as the core meaning of the proposition, the part that can be questioned or negated, and Hooper \& Thompson argue that assertion is the crucial property that licenses RTs in embedded clauses; for an embedded clause to be compatible with RTs, it must be asserted. Factive complements are presupposed, not asserted, thus, they are not compatible with RTs. While assertion is generally considered to be a property of main clauses, Hooper \& Thompson show that it can also be a property of embedded clauses and demonstrate that some clausal complements may be asserted, as in the case of semi-factives. Accordingly, factive complements that are asserted allow RTs, whereas factive complements that are presupposed do not permit RTs. Adopting the semantic label Assert for Force will, however, lead to other problems, as a reviewer suggests. One potential problem is that the labeling Force as Assert cannot be extended to embedded interrogative sentences. 
specification of force is marked by a separate morpheme, the declarative marker $-t a$ in $(9 a)$ and the interrogative marker -nya in (9b).

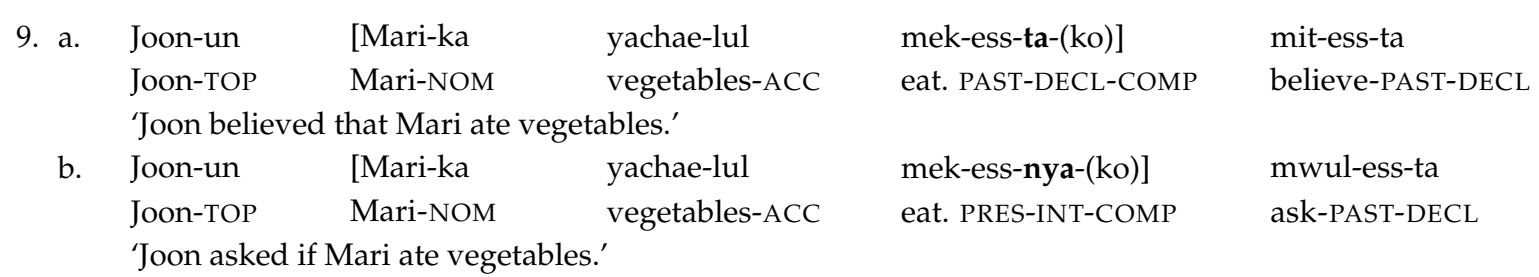

It is generally assumed in the literature that $k o$ is a COMP and merges as a $C$ head [29-32], but Shim and Ihsane [33] analyze the COMP $k o$ as a functional category higher than Force, corresponding to Report, a functional category which was proposed to represent the Japanese COMP to [34]. Thus, the function and property of COMPs seem to differ from language to language and the left periphery of $\mathrm{CP}$ needs to be further investigated. ${ }^{9}$

\subsection{Factive Clausal Complements}

The structures in (6) represent clausal complements of non-factive predicates, where the overt COMP that and the null COMP alternate. However, they cannot be the underlying structures of clausal complements of strong factive predicates such as regret, which do not permit COMP deletion. In other words, the FinP clausal complement in (6b) cannot be selected by true factive predicates such as regret or semi-factive predicates if the speaker does not allow a null COMP. The structure in (6a) is also problematic to represent the structure of factive complements when the COMP is overt. As mentioned earlier, RTs are impossible in the complement of regret and many speakers do not accept RTs in other semi-factive predicates even if the COMP is overt. If (6a) represented the underlying structure of clausal complements of both non-factive and factive predicates, it is mysterious why Topic and Focus can be projected under non-factive predicates, but cannot under factive predicates.

Haegeman suggests a way to solve this mismatch between factive and non-factive complements, and argues that the head Force is the locus of "speaker deixis", which encodes the anchoring of the proposition to the speaker [22]. In complements of factive predicates, speaker deixis is arguably lacking and the factive reading arises from the lack of speaker deixis. Based on this, she proposes a reduced CP structure for clausal complements of factive predicates, where ForceP is not projected. Assuming that Topic and Focus are licensed by speaker deixis (of the Force head), neither TopP nor FocP are projected when Force is missing in the structure.

Haegeman's reduced/truncated CP structure explains why Topic and Focus seem to be missing in the clausal complement of a factive predicate, but she does not clarify where the COMP that is located in the structure when the head Force is missing, as shown in (10) (with Mod standing for Modifier). ${ }^{10}$ In other words, (10) suggests that the COMP that is above FinP but it is not located under Force. ${ }^{11}$
10. That
$\operatorname{Mod}^{*}$
Fin
[23] (p. 1665)

9 Haegeman [22], for instance, proposes the head Sub(ordinator), distinguished from Force, where the subordinating conjunction elements originate.

10 De Cuba [23] makes a similar proposal on the distinction between factive and non-factive complements: while non-factive complements have a full-fledged $\mathrm{CP}$ structure, $c \mathrm{P}$ and $\mathrm{CP}$, which roughly correspond to ForceP and FinP, factive complements have a smaller structure, where the higher $c \mathrm{P}$ is not projected. He argues that the COMP that can merge either as the $c$ head or the $C$ head. However, it is not clear on what conditions that spells out $c$ or $C$, and when it is not spelled out at all, leading to a null COMP.On the other hand, Basse [7] maintains the view that ForceP is projected both in factive and non-factive complements, with its head being spelled out as that. The difference between factives and non-factives lies in the absence and the presence of an assertion feature on Force, respectively.

11 In more recent work with Ürögdi [35], Haegeman abandons her earlier proposal that factive clausal complements have a reduced structure. Instead, they propose an operator movement analysis, which prevents RTs in factive clausal complements. RTs are not possible due to the interference of a null operator that moves from a position above TP to Spec, CP with the movement of other elements to this position, typically fronted arguments as observed in RTs. 
Adopting and adapting Haegeman's idea that the structure of factive clausal complements does not have a full-fledged CP and the COMP that is above Fin, we propose an alternate structure to represent the clausal complement of a factive predicate in (7), repeated below.

7.

$$
[d \mathrm{P} d=\text { that }[\text { FinP Fin }=\varnothing]]
$$

We propose that that in non-factive clausal complements and that in factive clausal complements differ in nature: the former is a finite (declarative) COMP and the latter is a weak demonstrative. Thus, a non-factive clausal complement headed by that is a ForceP, with the head Force lexicalized by that, as in (6a), whereas a factive clausal complement headed by that is a $d \mathrm{P}$, and the $d$ head is spelled out as that, as shown in (7). To put it differently, non-factive (that-) complements are clausal and factive (that-) complements are nominal, a view prevailing in generative linguistics $[1,8,19,21] .{ }^{12}$ To support the structure in (7) where a D element, such as a demonstrative or a determiner, is projected above the clausal/FinP complement, we provide cross-linguistic evidence showing that a determiner or a demonstrative appears before the COMP, as exemplified in (11).

\begin{tabular}{|c|c|c|c|c|c|c|}
\hline \multirow[t]{2}{*}{ 11. a. } & $\begin{array}{l}\text { man } \\
\text { I }\end{array}$ & $\begin{array}{l}\text { mi-dun-ar } \\
\text { DUR-knov }\end{array}$ & & $\begin{array}{l}\text { (in) ke } \\
\text { DEM COMP }\end{array}$ & $\begin{array}{l}\text { Giti mi-ā-d } \\
\text { DUR-come-3sG }\end{array}$ & Persian \\
\hline & \multicolumn{5}{|c|}{ 'I know that Giti is coming.' } & Modified from [38] (p. 6) \\
\hline \multirow[t]{2}{*}{ b. } & (to) & oti & perase & to & ksero & Modern Greek \\
\hline & $\begin{array}{l}\text { DET.ACC } \\
\text { COMP }\end{array}$ & $\begin{array}{l}\text { DET.ACC } \\
\text { COMP }\end{array}$ & passed-3sG & it. ACC & know-1SG & \\
\hline
\end{tabular}

'I know that he passed the exam.'

The examples in (11) provide morphological evidence of a D element combining with a COMP in a clausal complement. Although researchers do not converge in their views on how to analyze the internal structure of a sentential complement with an optional D element preceding the COMP, several scholars have proposed that the sentential complement with a D element should be analyzed as a DP (or a nominal structure) rather than a CP [38-40], the view that we adopt and adapt in order to analyze factive clausal complements headed by that in English.

The idea that a clausal complement may be optionally realized as a DP rather than a CP in English was taken by Takahashi [41], who proposes a covert determiner structure for clausal complements headed by that. Although English does not show an overt spell-out of a determiner or a demonstrative before the COMP that in a clausal complement, Takahashi claims that an English sentential complement is in fact a DP, in which the D head is realized by a covert determiner THE, as in (12).

12. [DP THE [CP that ... ]]

Takahashi proposes the structure in (12) to explain why a moved clausal/CP complement exhibits properties of DPs in its base-generated position; a moved clausal complement must involve a DP structure headed by a covert determiner. In (12), a clausal complement is analyzed as a DP structure

12 A reviewer asks what the featural differences are between "clausal" and "nominal" complements. Although it is an interesting question worth pursuing, we do not propose any featural analysis to distinguish between clausal and nominal complements. We simply use these terms to describe syntactic differences found between non-factive complements and factive complements in accordance with what others say. More specifically, factive clausal complements may show syntactic behavior similarly to nominal complements. One way to distinguish between "clausal" and "nominal" complements could be to adopt a relativization structure for factive complements. The idea that factives are relative clauses has been proposed for Kwa languages [36,37] on the basis of examples where an argument DP or an entire VP is fronted to Spec, CP in factive clauses. Aboh extends this analysis to German and French factive clauses, where, he assumes, a null operator, rather than an overt constituent, moves to Spec, CP [36]. The relativization approach was further adopted by Haegeman and Ürögdi [35], who account for differences found between clausal complements of factive and non-factive verbs, including various RT phenomena or absence thereof. If we adopt this view, factive complements are relativized clauses with the null nominal head (the original idea goes back to [1]), whereas non-factive complements are not relativized. The details need to be worked out (e.g., presence/absence of a null operator), which we leave for future research. 
where a null D head takes a CP complement. This is in line with our view of analyzing clausal complements headed by that as a nominal structure in (7). Yet, we limit this analysis to clausal complements of factive predicates only, not those of non-factive predicates; there is no nominal layer in non-factive clausal complements. Also, the structure we propose in (7) significantly differs from (12) in that that lexicalizes the $d$ head, not C. In what follows, we will show that the $d P$ structure in (7) explains several peculiar facts found in factive clausal complements, such as speaker variation in obligatory vs. optional presence of that and the lack of RTs.

As has long been advocated in the literature, many speakers do not accept the omission of that in factive clausal complements, whereas they allow that deletion in non-factive clausal complements. The $d \mathrm{P}$ structure in (7) can explain why that is obligatory under factive predicates, unlike non-factive predicates: a factive predicate selects a nominal complement, a $d \mathrm{P}$, whose head is lexicalized by that. On the other hand, a non-factive predicate selects a clausal complement, either a ForceP or a FinP. When it selects a ForceP, the complement is headed by that. When it selects a FinP, the complement is null-headed, leading to a that-less clause.

Then how do we exclude the projection of Topic or Focus in the $d \mathrm{P}$ structure in (7)? In order to explain this, we further elaborate our claim that that in (7) is a weak demonstrative, distinguished from a strong demonstrative that: that is a weak, light demonstrative in the sense that it lacks $\varphi$-features in (7) in contrast with a strong demonstrative that with $\varphi$-features. A strong demonstrative that has a plural form those, showing $\varphi$-feature/number agreement with the following nominal element (e.g., that woman vs. those women). But that in sentential complements has no plural counterpart. ${ }^{13}$

13. we think that/*those you're wrong [44] (p. 112)

Also, the claim that the $d$ head lexicalized as that in (7) is a light, $\varphi$-feature lacking head, distinguished from a (strong) D head, has a consequence in syntactic derivations, disallowing the projection of Topic or Focus above FinP in (7). Based on word order in French and Hungarian nominals, Ihsane and Puskás [45] propose a split DP structure, where two DPs, a Det(erminer) Phrase and a Def(inite) Phrase, correspond to ForceP and FinP in Rizzi's split CP structure respectively. Parallel to the clausal domain, Topic and Focus may optionally appear between DetP and DefP, as shown in (14).

14. DetP (Topic) (Focus) DefP

They further argue that specificity and definiteness are separate notions and encoded on different functional heads, Topic and Def, respectively. They further assume that demonstratives have [+specific, + definite] features which merge under Def and move up to Topic. Since $\varphi$-features are not employed in their nominal system, the role of $\varphi$-features with respect to movement of demonstratives is not discussed in [45]. Yet, we pursue the distinction between strong and weak demonstratives in English and argue that the weak demonstrative that in (7) does not move in the course of derivation but remains in situ, due to the lack of certain features, such as $\varphi$-features. In contrast, strong demonstratives move further up to Topic (or even higher). This means that the $d \mathrm{P}$ in (7) headed by that, a weak/light / $\varphi$-feature lacking demonstrative, is structurally lower than Topic and Focus in (14). In other words, Topic and Focus may optionally appear above $d \mathrm{P}$, not between $d \mathrm{P}$ and FinP in (7). Nonetheless, the projection of Topic is not allowed above $d \mathrm{P}$, as demonstrated in (15). The ungrammaticality of topicalization above $d \mathrm{P} /$ that complements in (15) is due to the fact that TopP

13 Similarly, this cannot be used as a complementizer, as pointed out to us by an anonymous reviewer. According to Kayne [42], the complementizer that, the relative that, and the demonstrative that are all instances of the demonstrative that synchronically. More precisely, relative that is an instance of demonstrative that and sentential that is a subcase of relative that. This cannot be used as a complementizer due to the fact that there is no relative pronoun this. Although this unitary analysis is attractive, there seems to be counter-evidence from different languages [43]. As mentioned in footnote 12, a relativization analysis of factive complements (in contrast to non-factive complements) may be an interesting way to distinguish between nominal and clausal complements. 
cannot be selected by the matrix predicate, as explained earlier to account for unavailability of RTs in a null that clausal complement.

15. *Dean knows/realizes/regrets vegetables that Lily doesn't eat

A reviewer mentions that in contexts known as "emphatic topicalization" (ET) non-wh XPs can move to the left of the complementizer in languages/dialects such as Southern German and Bangla [46], a sequence that should be ruled out by (7). It is further noted, however, that when ET occurs in these languages, it further triggers movement of the topicalized CP to the front of the clause that immediately dominates it for convergence; in other words, the examples such as (15) are allowed neither in English nor Southern German and Bangla. The reason that (15) is not possible in all of these languages can be explained by our earlier statement; TopP cannot be a complement.

While such a derivation crashes in English, in languages such as Southern German and Bangla, there is a way to salvage it; the entire TopP must move to the left periphery to the clause. Bayer calls this "emphasis" [47], which is triggered by some type of Topic feature on C. If we adopt this analysis, languages vary concerning the process of emphasis.

Our proposal that that in factive clausal complements is a light or weak demonstrative lacking $\varphi$-features can be further supported by cross-linguistic facts from Korean, which shows similar distributional patterns of the COMP. In Korean, both factive and non-factive complements are headed by the COMP $k o$. Similar to that, $k o$ may be optional under non-factive predicates, but it is strongly preferred under factive predicates. ${ }^{14}$

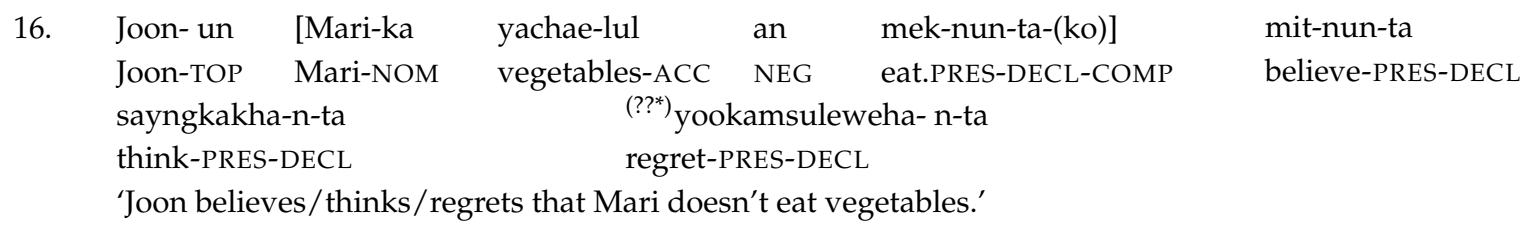

In addition, similar to that in English, the COMP ko may also be used as a demonstrative in modern Korean. When it is used as a demonstrative, however, it seems to lack $\varphi$-features in stark contrast to other types of demonstratives. As shown in (17), Korean has three types of definite descriptions/demonstratives: $i$ 'this' (a proximal form), $k u$ 'the' or 'that' (a neutral form: close to the hearer or known to both the speaker and the hearer), and $c e$ 'that' (a distal form). In (17b), ko may be used instead of the demonstrative/definite marker $k u .{ }^{15}$

14 Similar to that, there is speaker variation with ko deletion under factive predicates. While several informants of ours allow omission of $k o$ in all of three predicates, a reviewer judges that $k o$ deletion is only possible with strong non-factive predicates, such as 'think', not with predicates such as 'believe' (marginal) or 'regret' (unacceptable).

15 A reviewer asks whether there is any independent evidence that $k o$ is used as a demonstrative in Korean and ko in (17) is not an accidental homonym. If one takes this stance, the same question should be applied to that in English, which can be used a COMP and as a demonstrative. It is well documented that demonstratives have grammaticalized as complementizers in many languages, especially in the Germanic language family. Although Korean is not a member of this language family and there is little diachronic evidence showing that the COMP ko originates from a demonstrative, $k o$ is synchronically used as a COMP as a demonstrative in modern Korean, showing a similar distributional pattern with many other languages around the world. 


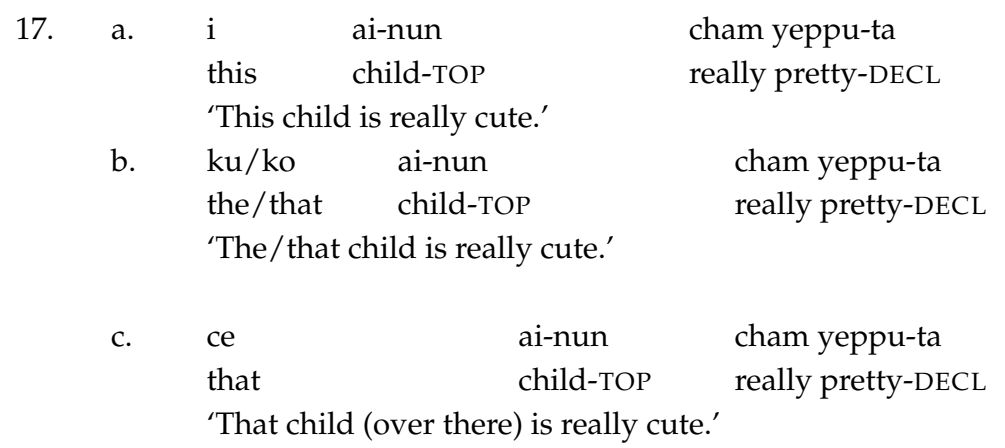

Similar to English demonstratives such as this and that, the demonstratives in Korean may be used as pronouns and be inflected by the plural morpheme tul. What is striking is that unlike other demonstratives, $k o$ cannot be inflected by the plural morpheme $t u l$ in $(18 \mathrm{~b})$, which strongly suggests that $k o$ is lacking $\varphi$-features. ${ }^{16}$

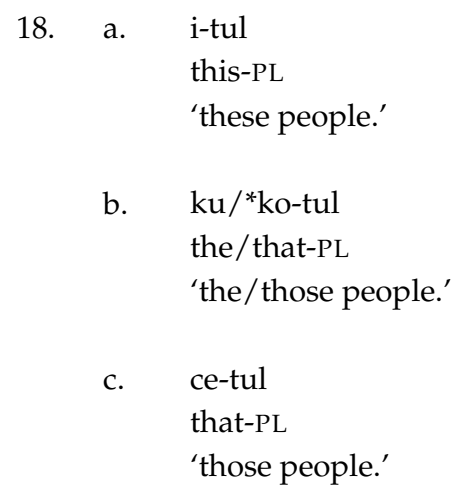

Thus, the existence of the $\varphi$-feature lacking demonstrative $k o$ in Korean, which is also used as a COMP in a clausal complement, supports our hypothesis that that is a $\varphi$-feature lacking demonstrative in (7).

The proposal that factive complements are light $d$ Ps in contrast with strong DPs can also explain why factive complements and DPs share some properties, but not all. For instance, factive complements are weak islands $[5,7,21]$ whereas DPs are strong islands for object extraction, as in (19). Also, factive complements can be complements of adjectives but not of prepositions in contrast with DPs [35], as exemplified in (20). Thus, it seems that there is a difference between light $d$ Ps and DPs regarding their distributions and syntactic behavior, which needs to be investigated further.

19. a. ?What did you regret [ap that John stole]?

[7] (p. 54)

b. $\quad$ What did you believe [DP the claim that John stole]?

20. a. I was surprised $[d \mathrm{P}$ that he left]

b. $\quad *$ John forgot about $[d \mathrm{P}$ that Jane left too early $]$

In this section, we have proposed that factive complements have an underlying structure distinguished from non-factive complements. Factive complements are $d$ Ps, where the light $d$ head is lexicalized by a weak demonstrative that. On the other hand, non-factive complements are either ForcePs when the COMP is overt and FinPs when the COMP is null. The underlying structure for factive complements in (7) was proposed based on different syntactic behavior exhibited by factive complements, in particular the obligatory presence of the COMP and the lack of RTs, as reported

16 Unlike plurality, neither person nor gender features are morphologically marked in Korean. 
in the literature. However, as noted earlier, some speakers allow COMP deletion and RTs in factive complements, and interestingly, they are limited to so-called semi-factive predicates, which lose their factivity in certain contexts (i.e., they lose their presupposed reading).

Thus, it seems that there is speaker variation regarding their judgment of factive complements. For those who have a clear cut between factive and non-factive predicates but do not differentiate between factive and semi-factive predicates with respect to COMP deletion and the allowance of RTs, (6) represents non-factive complements and (7) represents factive complements. On the other hand, for those who distinguish between true/strong factives and semi-factives, with the latter mimicking non-factives, the structure in (6) may represent non-factive and semi-factive predicates. Alternatively, we can think that both true factive complements and semi-factive complements have the $d \mathrm{P}$ structure in (7), distinguished from non-factive complements. Yet, the structure of semi-factives may be less impoverished/truncated than that of true factives, and contain a type of TopP allowing RTs. ${ }^{17}$ If this analysis holds true, we predict that there will be further differences found between true factives and semi-factives for their syntactic behavior, which we plan to investigate in the future.

\subsection{Interplay between Matrix Predicates and Complements}

To account for the distribution of overt and null COMPs in clausal complements of non-factive and factive predicates, we have proposed three different underlying structures of (a) overt that non-factive complements, (b) overt that factive complements, and (c) null that non-factive and factive complements, repeated in $(19 a-c)$, respectively.

21. $\quad$ a. $\quad[$ ForceP Force $=$ that $($ Topic $)($ Focus $)[$ FinP Fin $=\varnothing]]$

$$
\begin{array}{ll}
\text { b. } & {[d \mathrm{P} d=\text { that }[\text { FinP Fin }=\varnothing]]} \\
\text { c. } \quad[\text { FinP Fin }=\varnothing]
\end{array}
$$

The head Force in an embedded clause may be spelled out by different lexical items, such as that in declaratives and if or whether in questions in English. We have proposed that declarative force is the unmarked clause type at the level of FinP. Declarative sentences can be either asserted or presupposed, and it is widely assumed that non-factive complements are asserted regardless of the presence or absence of the COMP and factive complements are presupposed. Under our proposal that postulates different structures for overt that and null that complements, as in (21), one may wonder how the clausal complement without an overt COMP (21c) can be interpreted as assertion in the absence of a ForceP in its structure.

22. a. Dean believes/says/thinks [ForceP that Lily went to Paris last year]

b. Dean believes/says/thinks [FinP Lily went to Paris last year]

Under our proposal that declaratives are the unmarked type at the level of FinP, it is not problematic. The clausal complements in (22), with or without the COMP, are semantically asserted under non-factive predicates. However, it becomes more complex if factive complements with a null COMP are taken into account. When the COMP is null, both non-factive and semi-factive

17 It could be one of the projections in the hierarchy of topics advocated in Frascarelli and Hinterhölzl [48]. This projection could also be projected in the structure of examples considered as true factives by the authors, like (iii), although this not uncontroversial [35].

iii. I am glad that this unrewarding job, she has finally decided to give up [49] (p. 69)

As our focus here is on the null/overt COMP (non-)alternation, we leave the question open. What is important to us is that the structure of factive clausal complements is nominal. 
complements have the same structure of (21c). Yet, a non-factive complement is asserted whereas a factive complement is presupposed, as shown in (23).

23. a. Dean believes/says/thinks [FinP Lily went to Paris last year] assertion

b. Dean knows/realizes [FinP Lily went to Paris last year] presupposition

To account for this, we take the stance that by default a declarative clausal complement is asserted when it is selected by a non-factive predicate, whereas it is presupposed when it is selected by a factive predicate. The semantic/pragmatic information of the complement, whether it is asserted or presupposed, is not affected by the presence or the absence of the COMP. In this paper, we have postulated different syntactic structures for clausal complements with an overt COMP and a null COMP, a ForceP or a $d \mathrm{P}$ for the former and a FinP for the latter. Since both overt that and null that complements are asserted under non-factive predicates, as in (22), the presence of a ForceP in a declarative complement per se does not determine that the complement is asserted; both the ForceP in (22a) and the FinP in (22b) are asserted; the assertive reading of the complement comes from the non-factive matrix predicate. In the same vein, whether the complements in (23) are asserted or presupposed depends on the predicate selecting them: when the matrix predicate is non-factive, the complement is asserted, as in (23a). On the other hand, the complement is presupposed if it is selected by a factive predicate, as in (23b).

We close this section by mentioning some interesting cross-linguistic facts regarding an interaction between the matrix predicate and its complement. Shim and Ihsane argue that the presupposition of clausal complements is not solely determined by the type of the matrix predicate but rather influenced by an interplay between the type of a matrix predicate and the type of a clausal complement, based on various syntactic and semantic patterns of clausal complements in Korean [18]. Korean has three types of clausal complements, (a) the ko clause, (b) the kes clause with an overt tense morpheme and a (declarative) force marker, and (c) the kes clause without an overt tense morpheme and a force marker, as exemplified in $(24 \mathrm{a}-\mathrm{c})$, respectively.

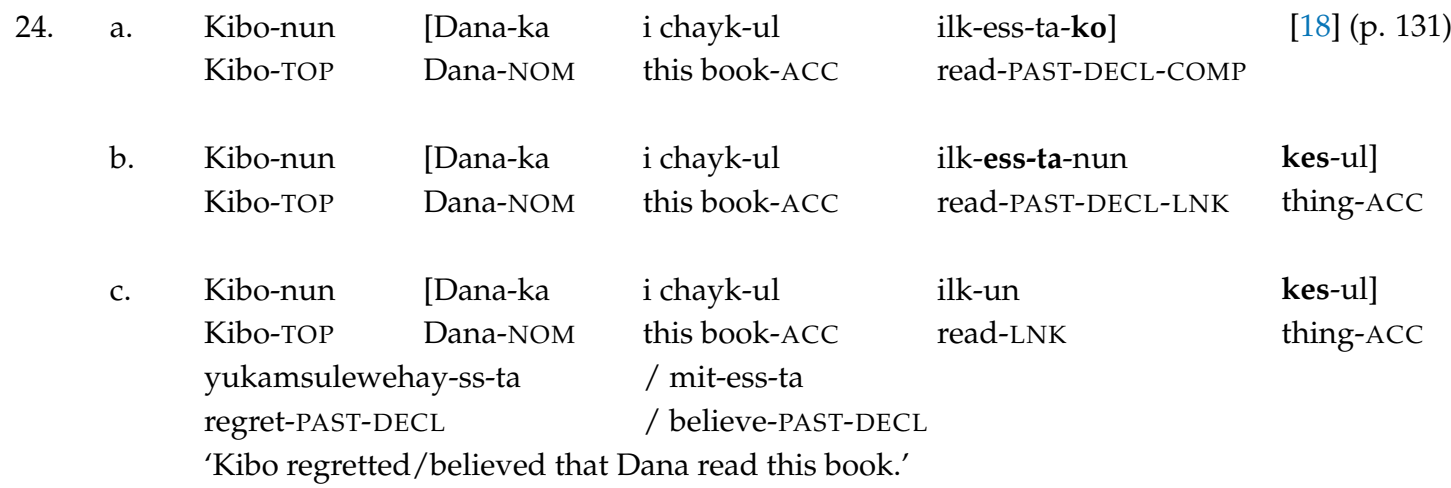

What is interesting in the examples in (22) is that all three types of complements of the factive verb yukamsuleweha 'regret' are presupposed, but not all of the complements of the non-factive predicate mit 'believe' are asserted; more specifically, the ko complement in (23a) and the kes complement with an overt tense morpheme and a (declarative) force marker in (23b) are asserted, whereas the kes complement without an overt tense morpheme and a force marker in (23c) are presupposed under the non-factive verb mit. This suggests that factivity and presupposition may not be as closely tied to each other as widely believed, and Shim and Thsane argue that the presuppositional reading of clausal complements is not solely determined by the nature of the matrix predicate, but is derived from two related factors, namely the type of a matrix predicate (factives or non-factives) and the type of its complement in Korean [18].

At first glance, the distinction between factive complements and non-factive complements seems to be rather clear in English, unlike Korean; the former is presupposed and the latter is not. But English 
too suggests that factivity and presupposition may be loosely related, as opposed to what is widely assumed in the literature. The example in (23) embeds a nominal complement, whose head fact further embeds an overt that clause, indicating that it is a factive complement.

25. $\quad{ }^{(*)}$ Dean denies/doubts the fact that Lily doesn't eat vegetables

Yet, the judgment of the sentence in (23) differ among our informants. While a few speakers judged it unacceptable, stating that the factive complement cannot be negated, most speakers fully accepted it, which suggests that a factive complement may not be always presupposed. Taking these facts all together, we conclude that the presupposition/assertion reading of clausal complements should not be taken in isolation, but their selectional environment, including the matrix predicate, should be considered.

\section{Conclusions}

In this paper, we have proposed that factive clausal complements and non-factive clausal complements have different underlying structures; while factive complements are $d$ Ps whose head is lexicalized by a weak demonstrative that, non-factive complements are either ForcePs (when the COMP that is present) or FinPs (when the COMP is null). This novel approach is in line with the extant proposals that the structure of overt that complements is more complex than the structure of null that complements and that the structure of non-factive that complements is richer than the structure of factive that complements. Our analysis further provides an explanation for the distribution of overt that clauses and null that clauses outside sentential complementation. As shown in (26), for instance, a sentential subject must be headed by that.

26

$$
\begin{aligned}
& \text { a. *(That) Lily doesn't eat vegetables is well-known factive } \\
& \text { b. } \quad * \text { (That) Lily doesn't eat vegetables is well-known non-factive }
\end{aligned}
$$

To account for the obligatory presence of that in (26), we adopt the following two proposals available in the literature. First, a sentential subject headed by overt that is not at Spec, T(ense)P but occupies the Topic position linked to a null DP at Spec, TP [20,50], as illustrated in (27). ${ }^{18}$

$$
\begin{aligned}
& \text { a. } \left.\quad\left[\mathrm{TopP}_{d \mathrm{P}} \text { That Lily doesn't eat vegetables }\right]_{i}\left[\mathrm{TP}_{\mathrm{DP}} \varnothing_{i} \text { is well-known }\right]\right] \\
& \text { b. } \quad\left[\text { TopP }[\text { ForceP That Lily doesn't eat vegetables }]_{i}\left[\text { TтP }_{\text {DP }} \varnothing_{i} \text { turns out to be false }\right]\right.
\end{aligned}
$$

We also take a syntactic derivational approach to information structure proposed by López [53]. López (re)defines the notions of Topic and Focus as Anaphor and Contrast and argues that syntactically dislocated constituents, such as left or right dislocates or hanging topics, are strong anaphors, having an antecedent in the previous discourse or the immediate context. Based on this view, we suggest that the element occurring in the Topic position should be a strong anaphor in order to be linked to an antecedent. López further proposes that a discourse anaphoric constituent bears the feature [+a(naphoric) ], which is assigned at the syntax-pragmatic interface.

Kim also makes a similar proposal to ours and argues that clausal subjects are in fact Topics, which are referential and bear [+nominal] feature [54]. If we adopt this analysis, the sentential subject in (27a) is a $d \mathrm{P}$, thus nominal, and it can be a Topic. But the sentential subject in (27b) is not nominal, yet it still serves as Topic. Thus, we depart from him and suggest an alternate way.

Building on the view that the COMP that originates as a demonstrative [42], we argue that the Force head lexicalized as that can be referential. To put it differently, both the $d$ head and the Force head lexicalized by that in (27a) and (27b) can serve as Topic.

18 This contrasts with other studies that treat clausal subjects as occurring in the canonical subject position, i.e., Spec, IP/TP (cf. Rosenbaum [51], Emonds [52] among others). We thank a reviewer for highlighting Rosenbaum's work. 
The idea that for a sentential subject to serve as Topic it should be anaphoric can be further supported by the structures proposed in (21) and our earlier proposals that a functional category lexicalized by that has a $d$-feature. Overt that clauses are either ForcePs or $d \mathrm{Ps}$, whose head bears a $d$-feature, whereas null that clauses are FinPs, lacking a $d$-feature. Hence, null that clauses cannot serve as Topic, which explains its absence at the sentence subject position.

It has been documented in the literature that RTs are not allowed in clausal subjects regardless of the presence of the COMP, as in (28).

28. a. *That this book Mary read thoroughly is true [55] (p. 332)

b. *That Mary your antics will upset is obvious [20] (p. 179)

The example in (28a) is a factive sentence, and the ban on argument fronting in the that clause can be explained by the proposal that the sentential subject in (28a) is a $d \mathrm{P}$, inside which Topic and Focus cannot be projected. ${ }^{19}$ On the other hand, it is not clear whether the example in (28b) is factive or not. If it is not factive, the sentential subject has the ForceP structure of (21a), in which RTs should be allowed, contrary to fact.

Based on the examples in (28), De Cuba argues that only factive complements, but not non-factive complements, can appear at the subject position [23].

29. a. [That there are porcupines in our basement] makes sense to me

b. *[That there are porcupines in our basement] seems to me

However, we suspect that the contrast found in (29a) and (29b) has nothing to do with factivity but is due to the different syntactic behavior of the matrix predicates, make sense and seem, the latter of which does not allow raising of the that clause from its underlying position. Yet, if it is true that only factive complements can serve as subject, as De Cuba argues, the ban on RTs in sentential subjects can be explained by the $d \mathrm{P}$ structure of factive that complements. Further research should be done to investigate this.

We conclude this paper by mentioning some puzzling data that seem to challenge our analysis of overt vs. null COMPs. In general, the COMP that is optional if the clausal complement is adjacent to the non-factive predicate, as in (30a). Yet, it is obligatory when the clausal complement is separate from its selecting predicate, as illustrated in (30b).

30. a. I believe (that) John liked linguistics

[56] (p. 39)

b. I believe very strongly *(that) John liked linguistics

Under our proposal that non-factive predicates select either a ForceP (overt that clauses) or a FinP (null that clause), it is indeed unexpected that the COMP is required when there is an intervening material between the matrix predicate and its complement. An [56] suggests that syntax alone cannot account for this behavior and offers a syntax-phonology account. He assumes that the null COMP is a result of PF (Phonetic Form) deletion of $\mathrm{C}$ and proposes that if a clause is obligatorily parsed as a separate intonational phrase (I-phrase), it cannot be headed by a null C (null C generalization, [56] (p. 58)). ${ }^{20}$ While a clausal complement in its canonical position, as in (30a), is optionally parsed as separate I-phrase, it is obligatorily parsed as a separate I-phrase at a non-canonical position in (30b); the clausal complement is extraposed to the right. Thus, the $C$ head cannot be null and it is spelled out as that.

In fact, our proposal is not in conflict with An's [56]. If his null C generalization holds true, it is predicted that overt that clauses can appear in non-canonical positions, for its head Force is lexicalized

19 (Be) true is non-factive according to Hooper and Thompson (Class A) [10], whereas be odd/strange is factive.

20 We thank a reviewer for referring to An's work [56]. 
by the COMP that. On the other hand, null that clauses are not allowed in this position, due to the fact that its Fin head is phonetically empty.

Acknowledgments: We would like to thank Languages and the two anonymous reviewers for their helpful comments. This research is supported by a Swiss National Science Foundation grant (\#100012_146699/1), which is gratefully acknowledged.

Author Contributions: The first author wrote the first draft of the paper, which underwent several revisions together with the second author.

Conflicts of Interest: The authors declare no conflict of interest.

\section{References}

1. Kiparsky, P.; Kiparsky, C. Fact. In Progress in Linguistics, 1st ed.; Bierwisch, M., Heidolph, K.E., Eds.; Mouton: The Hague, The Netherlands, 1970; pp. 143-173.

2. Stowell, T.A. Origins of Phrase Structure. Ph.D. Thesis, Massachusetts Institute of Technology, Cambridge, MA, USA, 1981.

3. Pesetsky, D. Zero Syntax Vol. 2: Infinitives. Available online: http://lear.unive.it/jspui/handle/11707/80 (accessed on 28 August 2017).

4. Bošković, Z.; Lasnik, H. On the Distribution of Null Complementizers. Linguist. Inq. 2003, 34, 527-546. [CrossRef]

5. Hegarty, M.V. Adjunct Extraction and Chain Configurations. Ph.D. Thesis, Massachusetts Institute of Technology, Cambridge, MA, USA, 1992.

6. Varlokosta, S. Factivity, factive complements and wh-extraction. MIT Work. Pap. Linguist. 1994, 23, 317-336.

7. Basse, G. Factive Complements as Defective Phases. In Proceedings of the 27th West Coast Conference on Formal Linguistics, Los Angeles, CA, USA, May 2008; pp. 52-62.

8. Haegeman, L. Locality and the distribution of main clause phenomena. In Locality, 1st ed.; Aboh, E.O., Guasti, M.T., Roberts, I., Eds.; Oxford Scholarship Online; Oxford University Press: Oxford, UK, 2014.

9. Karttunen, L. Some Observations on Factivity. Pap. Linguist. 1971, 4, 55-69. [CrossRef]

10. Hooper, J.; Thompson, S. On the applicability of root transformations. Linguist. Inq. 1973, 4, 465-497.

11. Sprouse, J.; Schütze, C.T.; Almeida, D. A comparison of informal and formal acceptability judgments using a random sample in Linguistic Inquiry 2001-2010. Linguist. Inq. 2013, 134, 219-248. [CrossRef]

12. Green, G. Main clause phenomena in subordinate clauses. Language 1976, 52, 382-397. [CrossRef]

13. Doherty, C. Clauses without That: The Case for Bare Sentential Complementation in English, 1st ed.; Routledge: Oxford, UK, 2000.

14. McClokey, J.; University of California, Santa Cruz, CA, USA. Adjunction, Selection and Embedded Verb Second. Unpublished work. 1992.

15. Emonds, J.E. A Transformational Approach to English Syntax, 1st ed.; Academic Press: New York, NY, USA, 1976.

16. Anderson, L.-G. Form and Function of Subordinate Clauses. Ph.D. Thesis, University of Gotenburg, Gotenburg, Sweden, 1975.

17. Heycock, C. Embedded root phenomena. In Blackwell Companion to Syntax, 1st ed.; Everaert, M., van Riemsdink, H., Eds.; Blackwell: Malden, MA, USA, 2006; Volume 2, pp. 174-209.

18. Shim, J.Y.; Ihsane, T. Facts: The interplay between the matrix predicate and its clausal complement. Newctle. Northumbr. Work. Pap. Linguist. 2005, 21, 130-144.

19. Hegarty, M.; University of Pennsylvania, Philadelphia, PA, USA. Familiar Complements and Their Complementizers: On Some Determinants of A'-locality. Unpublished work. 1992.

20. Alrenga, P. A sentential subject asymmetry in English and its implications for complement selection. Syntax 2005, 8, 175-207. [CrossRef]

21. Melvold, J. Factivity and definiteness. MIT Work. Pap. Linguist. 1991, 15, 97-117.

22. Haegeman, L. Conditionals, factives and the left periphery. Lingua 2006, 116, 1651-1669. [CrossRef]

23. De Cuba, C.F. On (Non)Factivity, Clausal Complementation and the CP-field. Ph.D. Thesis, Stony Brook University, Stony Brook, NY, USA, 2007. 
24. Rizzi, L.; Shlonsky, U. Strategies of Subject Extraction. In Interfaces + Recursion = Language? Chomsky's Minimalism and the View from Syntax-Semantics; Gärtner, H-M., Sauerland, U., Eds.; Mouton de Gruyter: Berlin, Germany, 2007; pp. 115-160.

25. Rizzi, L. The Fine Structure of Left Periphery. In Elements of Grammar; Haegeman, L., Ed.; Kluwer: Dordrecht, The Netherlands, 1997; pp. 289-330.

26. Roberts, I. Head movement. In The Handbook of Contemporary Syntactic Theory, 1st ed.; Steinberg, D.D., Jakobovits, L.A., Eds.; Wiley-Blackwell: Oxford, UK, 2008; pp. 112-147.

27. Cheng, L. On the Typology of Wh-Questions. Ph.D. Thesis, Massachusetts Institute of Technology, Cambridge, MA, USA, 1991.

28. Chomsky, N. The Minimalist Program, 1st ed.; MIT Press: Cambridge, MA, USA, 1995.

29. Choe, H.-S. Restructuring Parameters and Complex Predicates: A Transformational Approach. Ph.D. Thesis, Massachusetts Institute of Technology, Cambridge, MA, USA, 1988.

30. Ahn, H.-D.; Yoon, H.-J. Functional categories in Korean. In Harvard Studies in Korean Linguistics 3; Whitman, J., Kang, Y.-S., Lee, I.-H., Bak, S.-Y., Kim, Y., Kuno, S., Eds.; Harvard University Press: Cambridge, MA, USA, 1989; pp. 79-88.

31. Whitman, J. Topic, modality, and IP structure. In Harvard Studies in Korean Linguistics 3; Whitman, J., Kang, Y-S., Lee, I-H., Bak, S.-Y., Kim, Y., Kuno, S., Eds.; Harvard University Press: Cambridge, MA, USA, 1989; pp. 341-356.

32. Sells, P. Korean and Japanese morphology from a lexical perspective. Linguist. Inq. 1995, 26, 277-325.

33. Shim, J.Y.; Ihsane, T. English overt and null complementizers. Stud. Gener. Gramm. 2017. accepted.

34. Saito, M. Sentence Types and the Japanese Right Periphery. In Discourse and Grammar: From Sentence Types to Lexical Categories; Grewendorf, G., Zimmermann, T. E., Eds.; De Gruyter: Berlin, Germany, 2012; pp. 147-176.

35. Haegeman, L.; Ürögdi, B. Referential CPs and DPs: An Operator movement account. Theo. Linguist. 2010, 36, 111-152. [CrossRef]

36. Collins, C. The factive construction in Kwa. In Travaux de Recherche sur le Créole Haïtien; Lefebvre, C., Ed.; Départment de Linguistique, Université du Québec à Montréal: Montréal, Canada, 1994; pp. 31-65.

37. Aboh, E. Deriving relative and factive constructions in Kwa. In Contributions to the Thirtieth Incontro di Grammatica Generativa; Brugè, L., Giusti, G., Munaro, N., Schweikert, W., Turano, G., Eds.; Libreria Editrice Cafoscarina: Venice, Italy, 2005; pp. 265-285.

38. Farudi, A. An Antisymmertic Approach to Persian Clausal Complements. Available online: http://lear. unive.it/jspui/handle/11707/215 (accessed on 28 August 2017).

39. Roussou, A. Nominalized clauses in the syntax of Modern Greek. UCL Work. Pap. Linguist. 1991, 3, 77-100.

40. Aghaei, B. Clausal Complementation in Modern Persian. Ph.D. Thesis, University of Texas at Austin, Austin, TX, USA, 2006.

41. Takahashi, S. The hidden side of clausal complements. NLLT 2010, 38, 343-380. [CrossRef]

42. Kayne, R. Why isn't This a Complementizer? In Comparison and Contrasts; Kayne, R., Ed.; Oxford University Press: Oxford, UK, 2010; pp. 190-227.

43. Franco, L. Complementizers are not (Demonstrative) Pronouns and Vice Versa. Available online: http:/ / ling.auf.net/lingbuzz/001539 (accessed on 24 July 2017).

44. Roberts, I.; Roussou, A. Syntactic Change: A Minimalist Approach to Grammaticalization, 1st ed.; Cambridge University Press: Cambridge, UK, 2003.

45. Ihsane, T.; Puskás, G. Specific is not definite. Gener. Gramm. Geneva 2001, 2, 39-54.

46. Bayer, J.; Dasgupta, P. Emphatic Topicalization and the Structure of the Left Periphery: Evidence from German and Bangla. Syntax 2016, 19, 309-353. [CrossRef]

47. Bayer, J. Asymmetry in emphatic topicalization. In Audiatur Vox Sapientiae; Féry, C., Sternefeld, W., Eds.; Akademie-Verlag: Berlin, Germany, 2001; pp. 15-47.

48. Frascarelli, M.; Hinterhölzl, R. Types of topics in German and Italian. In Information Structure, Meaning and Form; Schwabe, K., Winkle, S., Eds.; John Benjamins: Amsterdam, The Netherlands, 2007; pp. 87-116.

49. Bianchi, V.; Frascarelli, M. Is Topic a Root Phenomenon? Iberia 2010, 2, 43-88.

50. Koster, J. Why subject sentences don't exist. In Recent Transformational Studies in European Languages, 1st ed.; Keyser, S.J., Ed.; MIT Press: Cambridge, MA, USA, 1978; pp. 53-64.

51. Rosenbaum, P.S. The Grammar of English Predicate Complement Constructions; MIT Press: Cambridge, MA, USA, 1967. 
52. Emonds, J. A reformulation of certain syntactic transformations. In Goals of Linguistic Theory; Peters, S., Ed.; Prentice-Hall: Englewood Cliffs, NJ, USA, 1972; pp. 21-62.

53. López, L. A Derivational Syntax for Information Structure, 1st ed.; Oxford University Press: Oxford, UK, 2009.

54. Kim, K.-S. Movement paradoxes are not paradoxes: A raising approach. Lingua 2011, 121, $1009-1041$. [CrossRef]

55. Authier, J.-M. Iterated CPs and embedded topicalisation. Linguist. Inq. 1992, 23, 329-336.

56. An, D.-H. Clauses in noncanonical positions at the syntax-phonology interface. Syntax 2007, 10, 38-79. [CrossRef]

(c) (C) 2017 by the authors. Licensee MDPI, Basel, Switzerland. This article is an open access article distributed under the terms and conditions of the Creative Commons Attribution (CC BY) license (http://creativecommons.org/licenses/by/4.0/). 